\title{
Analysis of Traffic Accident Dynamics at Semaphored Crossroads - a Case Study
}

\section{Tatjana Stanivuka, Mimo Draškovićb, Neven Kralj}

The paper deals with the analysis of dynamics of a traffic accident involving two vehicles and having happened at the semaphored crossroads in the afternoon hours i.e. when the traffic lights at the crossroads were functioning according to the programmed system and on the second programme. To prove the causes of the traffic accident, in analysing all the possible variants of the participants' motions through the semaphored crossroads, the 3D display was also used. The value of EES (Energy Equivalent Speed) represents the starting parameter for calculation of vehicle's speed in the instant of crash. Since the dynamics, or better to say motion of the participants in the traffic accident depends on properly working traffic lights, it is of great importance to present the work schedule of the traffic lights of the mentioned intersection, before we analyse the traffic accident itself. The control of all the results gained was carried out using computer programme package PC Crash 9.0 to simulate the crash. Great attention was also paid to the time intervals of vehicles' motions. Also, the possibility of having avoided the accident in question was analysed.

\section{KEY WORDS}

$\sim$ Dynamics of traffic accident

$\sim$ Vehicles

$\sim$ Crash simulation

$\sim$ Time intervals

\author{
a. University of Split, Faculty of Maritime Studies, Split, Croatia \\ e-mail: tstanivu@pfst.hr \\ b. Maritime Faculty of Kotor, Kotor, Montenegro \\ e-mail: rookie@t-com.me \\ c. Standing court expert, Mravince, Croatia \\ e-mail: nkralj969@gmail.com
}

\section{INTRODUCTION}

The framework of this paper is the analyses of the true facts gathered and noted at the sight of this severe traffic accident. The participants of the accident are two vehicles that crashed at the mentioned intersection equipped with traffic lights.

The traffic accident in question happened at the right angle crossroads of three streets, which in the following text will be referred to as: street $X$, street $Y$ and street $Z$, and at which the traffic is regulated with the use of semaphore.

The eastern traffic lane, on the southern direction of the crossroads, along which the vehicle A was moving, has the total width of $9.40 \mathrm{~m}$ and is divided into three traffic lanes. The vehicle A was moving along the left traffic lane which is used for the movement of vehicles turning left.

The western traffic lane on the southern direction of the crossroads is intended for the movement of vehicles from the opposite direction and is also divided into three traffic lanes.

The western traffic lane of the street $Z$ is divided into three traffic lanes. The right traffic lane, along which the vehicle $B$ was moving, is intended for the movement of vehicles maintaining the direction of movement or for vehicles turning right; the central lane is intended for vehicles which at the crossroads maintain the direction of movement, while the left lane is for the vehicles turning left at the crossroads.

At the moment of occurrence of the traffic accident the semaphores at the crossroads were functioning according to, i.e. when the traffic lights at the intersection are programmed for working during the afternoon hours. 


\section{POSITION, TRACES AND DAMAGES TO VEHICLES FOUND ON THE ROADWAY}

The northern part of the object on the eastern side of the roadway of the street $Z$ is considered as the fixed point of measurement (in further text: FPM), while the perpendicular drawn from FPM onto the western edge of the roadway is considered to be the initial point of measurement (in further text: IPM).

From IPM at $32.80 \mathrm{~m}$ start the traces of vehicle B's braking. The right hand side braking trace is distant from the western edge of the roadway by $0.7 \mathrm{~m}$, and extends linearly up to $52.30 \mathrm{~m}$ from IPM, at 0.20 m east of the imaginary line of the western edge of the roadway in street $Z$.

From IPM $52.30 \mathrm{~m}$, at the end of the right braking trace, chips were found on the roadway (point of vehicles' crash).

From IPM $51.60 \mathrm{~m}$, and $1.0 \mathrm{~m}$ to the east the front right part of the vehicle $B$ was found. The rear part was $52.40 \mathrm{~m}$ distant, the front left part $53.10 \mathrm{~m}$ and $0.40 \mathrm{~m}$ to the east. The vehicle $B$ is turned around with the front part toward north-west.

From IPM $48.30 \mathrm{~m}$ at the western part of the crossroads in the street $Y, 5.20 \mathrm{~m}$ to the west from the imaginary line of the western roadway lane of the street $Z$ the front right part of the vehicle $A$ was found, while the rear right part was $50.0 \mathrm{~m}$ distant and $9.15 \mathrm{~m}$ to the west.

From IPM $46.80 \mathrm{~m}$ and $9.0 \mathrm{~m}$ to the west, the front left part of the vehicle $A$ was found, and the same vehicle was turned around its front part to the east.

The traces left by the tires of vehicle $A$ are visible at the top of the street island dividing the roadway of the street $Y$, as well as the arch trace of drifting by the rear wheels of the vehicle $A$, with the length of $2.80 \mathrm{~m}$, while the top of the above mentioned island is to the west of the imaginary line of the street $Z$ at the distance of $7.90 \mathrm{~m}$. Around the point of crash traces are visible of chips originating from both vehicles (Baker et al., 1990; Čović and Zečević, 1987; Rotim, 1989; Rotim, 1992).

\subsection{Damages Suffered by Vehicle A}

The damage concentration on the vehicle $A$ is found at the right side of the vehicle (Figures 1 and 2) where the following parts suffered damage: front right door, rear right door, boarding step - right, right threshold, internal part of the right threshold, boarding of the passenger cabin - in the right part, pillar - central right and tire - rear right.

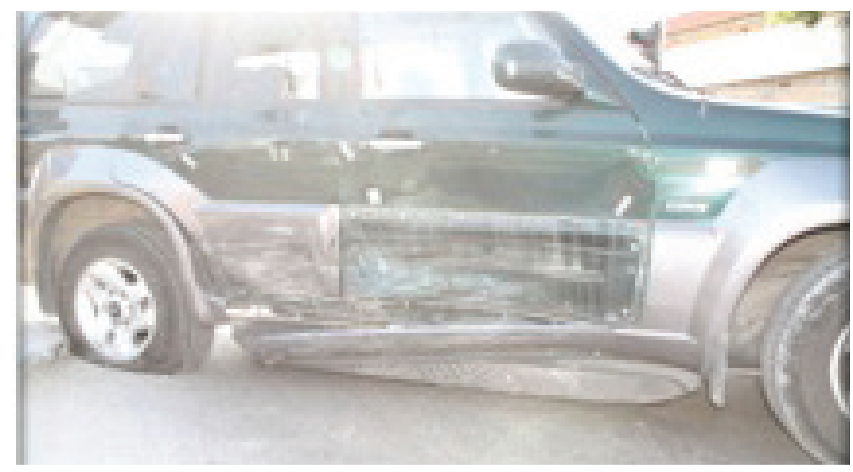

Figure 1.

Damages to vehicle $A$.

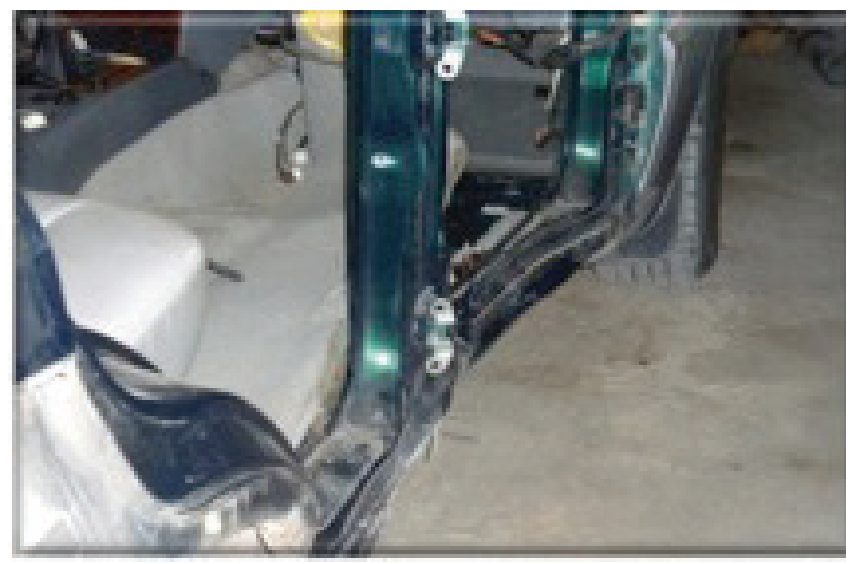

Figure 2.

Damages to the right pillar and threshold of vehicle $A$.

\subsection{Damages Suffered by Vehicle B}

The damage concentration on vehicle $B$ was found at the front part of the vehicle, mainly to the right (Figures 3 and 4), where the following parts were found damaged: the front bumper, front right reflector, grill, front lid, front panel, front right wheel casing, front right wheel was pushed to the front right pillar, crack in the windshield in the upper left corner in front of the driver's position, the steering wheel bent to the right while the vehicle's armature was displaced of the base, damage to the central part of the roof indicating deformation of the vehicle body, etc. 


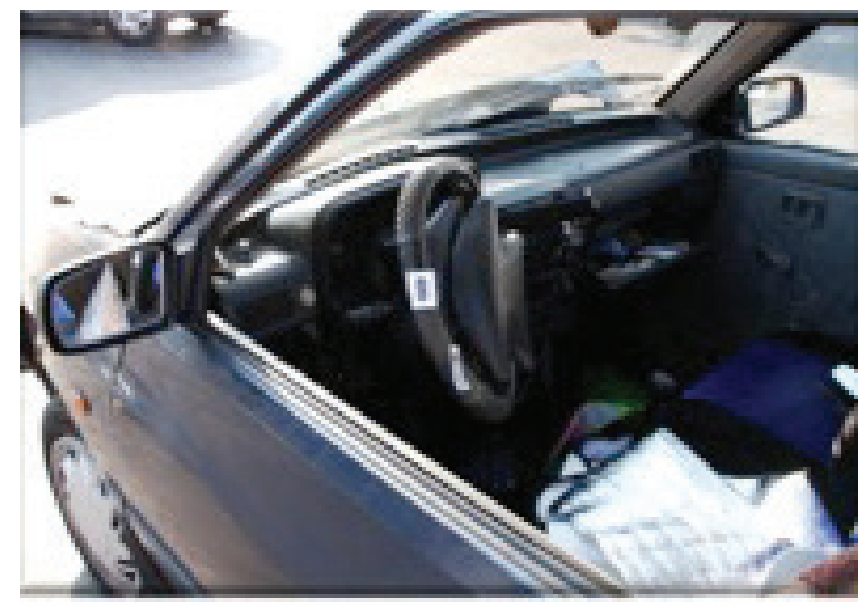

Figure 3.

Damages to vehicle $\mathrm{B}$.

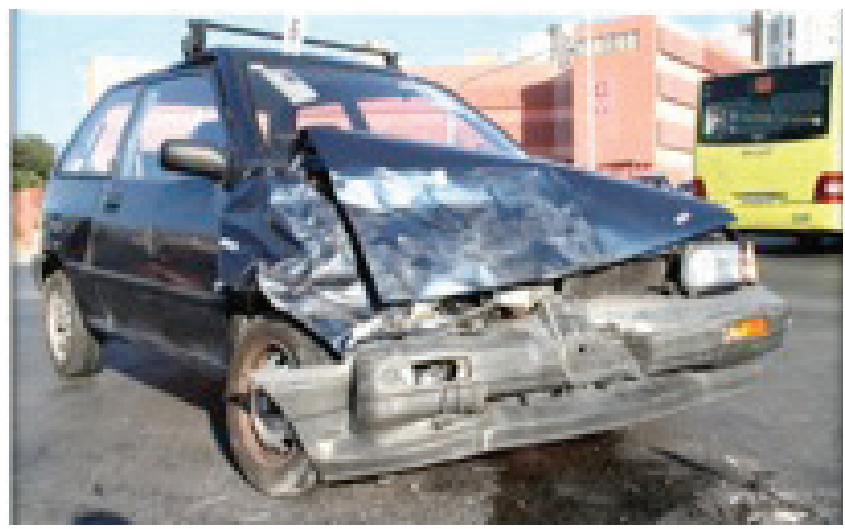

Figure 4.

Damages to vehicle B's interior.

\section{PLACE OF CRASH}

In the relative traffic accident the front part of the vehicle $B$ ran into the right side of the vehicle $A$.

The crash of the private vehicles will be determined as angular where, taking into consideration the longitudinal axes at the moment of crash, they made the angle of approximately $135^{\circ}$. The exact place of crash is at the crossroads, in the extension of the western roadway and western traffic lane of the street $Y$, at the distance of $49.00 \mathrm{~m}$ from PTM to the south and $7.0 \mathrm{~m}$ from the edge of the central island dividing the two roadway lanes of the street $Y$, also in the southern direction.

The place of the crash was determined by the end of the braking traces produced by the front wheels of the vehicle $B$ and the traces imprinted into the roadway as well as the stopped position of the vehicle B (Coyle, 2008).

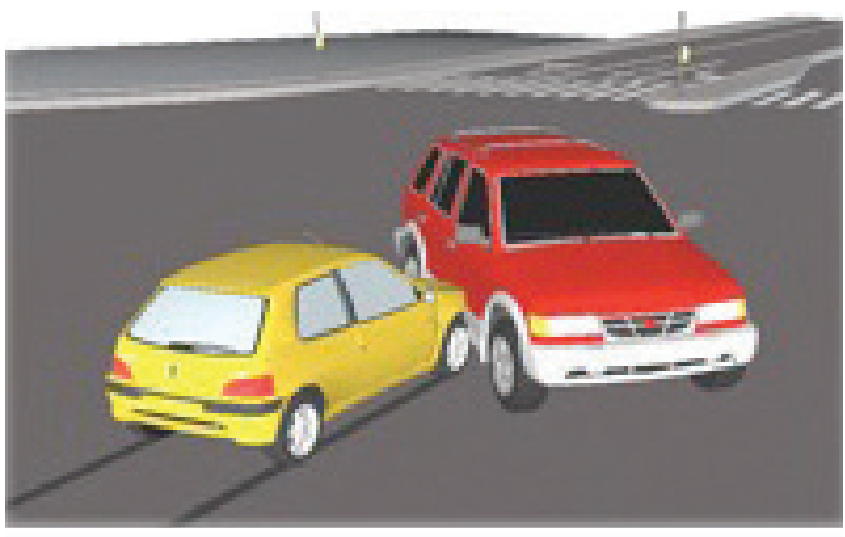

Figure 5.

Position of vehicles at the moment of crash

\section{SPEEDS AND TIME INTERVALS OF VEHICLES' MOVEMENTS}

\subsection{Speeds of Vehicle A and B Movements Using Energy Method}

The speed of the vehicles from the place of the crash to the final stopped position is calculated using the following formulae:

$k_{r}=\frac{r_{i}}{L}$

where:

$r_{i}$ - radius of rotation $[\mathrm{m}$ ],

$L$ - distance between axles $[m]$,

$k_{r}$ - rotation coefficient;

$\omega=\sqrt{\frac{a \cdot \varphi^{2}}{\varphi \cdot k_{r}\left(1-D_{k}\right)+\frac{s}{1.7}}}$

$v_{t}=1.7 \cdot\left[\frac{a \cdot \varphi}{\omega}-k_{r} \cdot \omega \cdot\left(1-D_{k}\right)\right]$

where:

$a$ - average deceleration obtained $\left[\mathrm{m} / \mathrm{s}^{2}\right]$,

$\varphi$ - vehicle angular motion [ $\mathrm{rad}]$,

$k_{r}$ - rotation coefficient,

$D_{k}$ - coefficient of deceleration force distribution,

$s$ - distance between vehicle's points of gravity in the crash and final positions $[\mathrm{m}]$,

$\omega$ - angular speed $\left[\mathrm{s}^{-1}\right]$,

$v_{t}$-speed immediately following the crash $[\mathrm{m} / \mathrm{s}]$ or $[\mathrm{km} / \mathrm{h}]$. 
By inserting the data obtained by measurements in the previously mentioned formulae the following results are obtained:

- From the point of crash to the final stopped position the vehicle A, whose distance between axles $(L)$ is $2.40 \mathrm{~m}$, was moving strongly rotating in the radius of $\left(r_{i}\right) 1.57 \mathrm{~m}$, and reached the rotation coefficient of $k_{r}=0.65$.

In doing so the vehicle's point of gravity made a longitudinal displacement $(s)$ of $7.5 \mathrm{~m}$, and an angular displacement $(\varphi)$ of $125^{\circ}$ i.e. 2.18 work, in which the realistic deceleration $(a)$ was 5.5 $\mathrm{m} / \mathrm{s}^{2}$ i.e. $D_{k}$ is 0.55 , and the angular velocity was $\omega=2.28 \mathrm{~s}^{-1}$.

Thus, the speed of vehicle $A$ immediately after the crash was:

$$
v_{t(A)}=7.81 \mathrm{~m} / \mathrm{s} \approx 28.12 \mathrm{~km} / \mathrm{h}
$$

- From the point of crash to the final stopped position the vehicle $B$, whose distance between axles $(L)$ is $2.30 \mathrm{~m}$, was moving with a significant rotation in the radius of $\left(r_{i}\right) 1.35 \mathrm{~m}$, and reached the rotation coefficient $k_{r}=0.59$.

In doing so the vehicle's point of gravity made a longitudinal displacement $(s)$ of $3.6 \mathrm{~m}$, and angular displacement $(\varphi)$ of $102^{\circ}$ i.e. 1.78 work, in which the realistic deceleration $(a)$ was $5 \mathrm{~m} / \mathrm{s}^{2}$ i.e. $D_{k}$ was 0.50 , and the angular velocity was $\omega=2,45 \mathrm{~s}^{-1}$.

Thus, the speed of the vehicle B immediately following the crash was:

$v_{t(B)}=4.95 \mathrm{~m} / \mathrm{s} \approx 17.82 \mathrm{~km} / \mathrm{h}$

On the basis of damages that the relative vehicles $A$ and $B$ suffered in the crash (Rotim, 1989; Rotim, 1992), and by comparison with Equivalent Energy Speed - EES catalogue (vehicle damage database), the following EES values are stated:

EES for $A \sim 8.33 \mathrm{~m} / \mathrm{s}$ or $30 \mathrm{~km} / \mathrm{h}$

EES for $B \sim 12.50 \mathrm{~m} / \mathrm{s}$ or $45 \mathrm{~km} / \mathrm{h}$

From the above mentioned the total deformation work in the crash (W) follows:

$W=\frac{m_{A} \cdot E E S^{2}}{2}+\frac{m_{B} \cdot E E S^{2}}{2}$

where $\mathrm{mA}=2,300 \mathrm{~kg}$ and $\mathrm{mB}=875 \mathrm{~kg}$ represent the masses of the vehicle $A$ and vehicle $B$, so that

$W=148,156.61[\mathrm{Nm}]$

The relative speed of the crash was approximately:

$$
\begin{aligned}
v_{r e l} & =\sqrt{2 \cdot \frac{m_{A}+m_{B}}{m_{A} \cdot m_{B} \cdot\left(1-D_{K}\right)} \cdot W}= \\
& =22.18 \mathrm{~m} / \mathrm{s} \approx 79.86 \mathrm{~km} / \mathrm{h}
\end{aligned}
$$

The changes in the speed of the vehicle $A\left(\Delta v_{A}\right)$ and the vehicle $\mathrm{B}\left(\Delta \mathrm{v}_{\mathrm{B}}\right)$ amounted about:

$$
\begin{aligned}
\Delta v_{A} & =\frac{m_{B}}{m_{A}+m_{B}} \cdot\left(1-D_{K}\right) \cdot v_{r e l}= \\
& =5.81 \mathrm{~m} / \mathrm{s} \approx 20.91 \mathrm{~km} / \mathrm{h}
\end{aligned}
$$

$$
\begin{aligned}
\Delta v_{B} & =\frac{m_{A}}{m_{A}+m_{B}} \cdot\left(1-D_{K}\right) \cdot v_{r e l}= \\
& =15.26 \mathrm{~m} / \mathrm{s} \approx 54.95 \mathrm{~km} / \mathrm{h}
\end{aligned}
$$

From the above mentioned it follows that at the moment of crash the vehicle $A$ had the moving speed of approximately:

$v_{A}=\Delta v_{A}+\Delta v_{t(A)}=13.62 \mathrm{~m} / \mathrm{s} \approx 49.03 \mathrm{~km} / \mathrm{h}$

and the vehicle B approximately:

$v_{B}=\Delta v_{B}+\Delta v_{t(B)}=10.31 \mathrm{~m} / \mathrm{s} \approx 37.12 \mathrm{~km} / \mathrm{h}$

Since at the roadway immediately before the point of crash there are no noticeable traces of braking or drifting by the vehicle $A$, then the moving speed of the vehicle $A$ immediately preceding the crash as well as the speed in the course of crash were approximately:

$v_{A}=13.62 \mathrm{~m} / \mathrm{s} \approx 49.03 \mathrm{~km} / \mathrm{h}$

The vehicle $B$, immediately prior to the crash, was moving in the phase of intensive braking in the length of $\mathrm{s}^{B}=19.5 \mathrm{~m}$ and in doing so, taking into consideration the conditions on the roadway, it could reach deceleration of $a_{\max }=7.00 \mathrm{~m} / \mathrm{s}^{2}$. Providing that onto the neutralized speed on the above mentioned braking path the speed in the crash is added, $v=10.31 \mathrm{~m} / \mathrm{s}$, se the speed of the vehicle B's motion at the moment of the driver's reaction to the brake will be obtained, and it is approximately:

$$
\begin{aligned}
v_{B_{\text {new }}} & =\sqrt{2 \cdot a_{\text {max }} \cdot s_{B}+v^{2}}= \\
& =19.48 \mathrm{~m} / \mathrm{s} \approx 70.11 \mathrm{~km} / \mathrm{h}
\end{aligned}
$$




\subsection{Inspection - Result Control}

The control of the obtained results of the moving speeds of the vehicles $A$ and $B$ was performed using the computer programme PC Crash 9.0 for the simulation of the crash, with which approximately equal results were obtained (Datentechnik, 2010; Kramer, 2006).

The graphic display of the programme simulation of the relative crash showed that the point of crash as well as the crash speeds were correctly determined. It was based on the facts that the vehicles in the programme simulation in the settling period following the crash process and with the calculated parameters inserted, were brought to the final, or stopped position identical to the one stated by the situational plan of the participants at the point of crash, as well as on the basis of the fact that the vehicles in their post-crash moving followed the roadway traces. The kinematics of the motion of the vehicles in the crash process and the settling period following the crash process is shown in the following Figure 6:

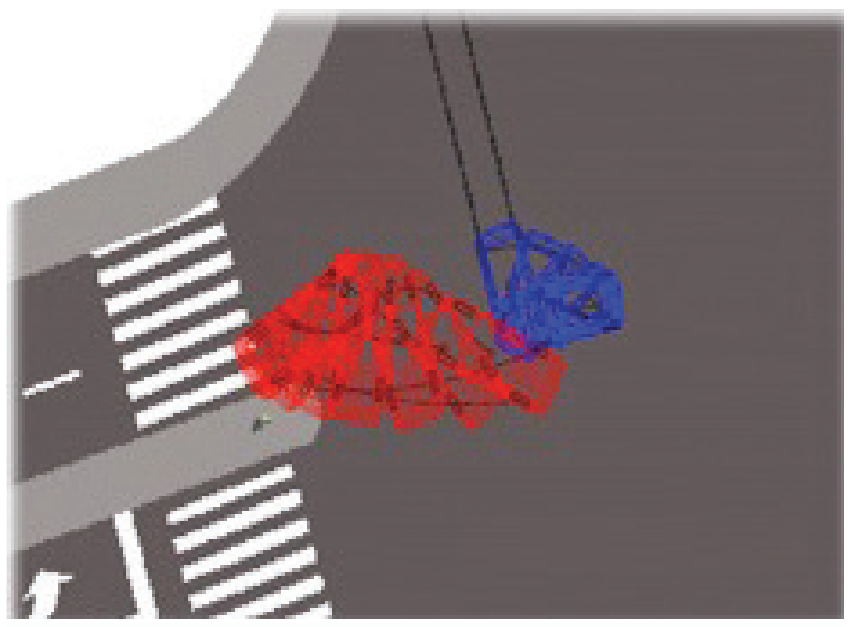

Figure 6.

Simulation of actual crash.

At the instant of rush of the vehicle $B$ with its front part onto the right side part of the vehicle $A$, the vehicle $B$ according to $P C$ Crash was moving at the speed of approximately $70 \mathrm{~km} / \mathrm{h}$, and the vehicle $A$ at the speed of approximately $49 \mathrm{~km} / \mathrm{h}$, which is within the permitted tolerance limits.

\subsection{Time Intervals of Vehicle Movement}

The total deceleration time of the vehicle $B$ from the moment of reaction of the driver to the brake to the moment of crash was:
$t=t_{s}+\frac{v_{B_{\text {new }}}-v_{B}}{3.6 \cdot a_{\text {max }}}=2.31 \mathrm{~s}$

The path which the vehicle $B$ traversed from the moment when the driver reacted to the brake to the place of the crash is:

$s=t_{s} \cdot \frac{v_{B_{\text {new }}}}{3.6}+\frac{v_{B_{\text {new }}}-v_{B}^{2}}{26 \cdot a_{\text {max }}}=2.31 \mathrm{~s}$

The vehicle $B$ was moving along the western roadway and western traffic lane of the street $\mathrm{Z}$ from the northern direction southwards at the moving speed of approximately $19.48 \mathrm{~m} / \mathrm{s} \approx$ $70.11 \mathrm{~km} / \mathrm{h}$ and approximately 2.31 seconds before the crash it was distant from the point of crash approximately $38.91 \mathrm{~m}$ in the northern direction, entirely located on the western traffic lane of the western roadway of the street $Z$.

In the same time interval the vehicle A was moving along the western traffic lane of the eastern roadway of the street $Z$ from the southern direction northwards at the moving speed of approximately $13.62 \mathrm{~m} / \mathrm{s} \approx 49.03 \mathrm{~km} / \mathrm{h}$ and was distant from the point of crash by approximately $31.46 \mathrm{~m}$ in the southern direction, entirely located on the western traffic lane of the eastern roadway of the street $Z$.

In the following Figure 7 a $3 \mathrm{D}$ view of the sequence of the occurrence of the traffic accident in the above mentioned moving intervals is shown (Datentechnik, 2010).

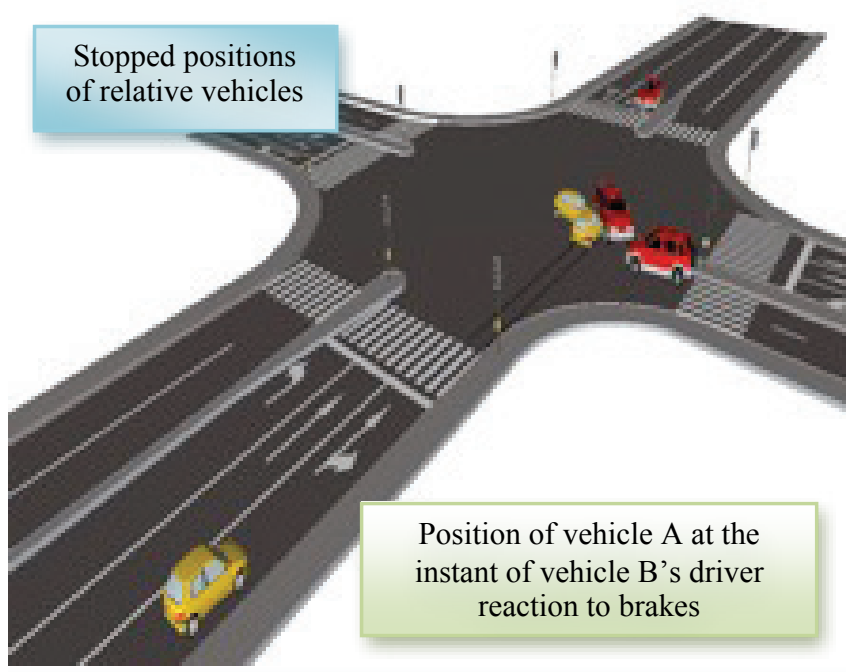

Figure 7.

3D display of the occurrence of traffic accident. 


\subsection{Possibility of Mutual Sighting}

Having taken into consideration all the parameters mentioned up to this point, appearance of the roadway in the form of quad arrow crossroads, the fact that in the course of the occurrence of the crash the weather was fair and sunny, a conclusion can be reached that the drivers of the vehicles $A$ and $B$ were able to sight each other at the distance of at least 100 meters before the place of crash in the direction of the motion of both vehicles (Zovak, 2007).

\subsection{Analysis of Light Signalling Operation at the Relative Crossroads}

For further analysis it was necessary to obtain data on the traffic lights operation. They were provided by the Traffic control and management center for the purposes of this paper. From the diagram (Figure 8) the traffic lights operational cycle of 75 seconds can be seen, while lights for directional movements of the relative vehicles exchange as shown below.

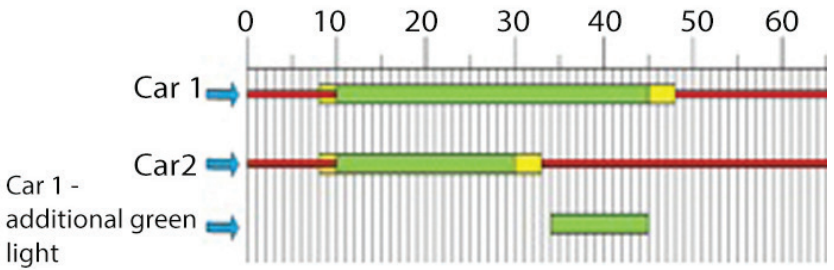

Figure 8.

Traffic lights operation.

\section{MODE OF CRASH OCCURRENCE}

The relative vehicle crash occurred due to the vehicle B's entering the crossroads in the stage of intensive braking, when its forward, more right-hand part crashed into the right-hand side of the vehicle $A$, which at that moment was proceeding in turning left and obstructed vehicle B in performing the turn.

The basic question of the relative traffic accident is: "Why did the vehicle B's driver react by intensive braking at the moment when vehicle $A$ had not even reached the pedestrian crossing at the other side of the crossroads?"

By a detailed analysis of the witnesses' statements, photos taken at the place of the accident, inspection of the place of the accident, as well as by the analysis of kinematic magnitudes of the relative traffic accident two possible modes of the occurrence of the relative traffic accident have to be analysed.

\subsection{Both Vehicles Pass With Green Light}

Concerning the exchange of light signalling at the relative crossroads it is obvious that there is a possibility that the relative traffic accident occurred due to both vehicles entering the crossroads with green light and in that case the vehicle A while turning left crossed the trajectory of vehicle B's movement when the crash occurred of the front part of the vehicle $B$ onto the right hand side part of the vehicle $A$.

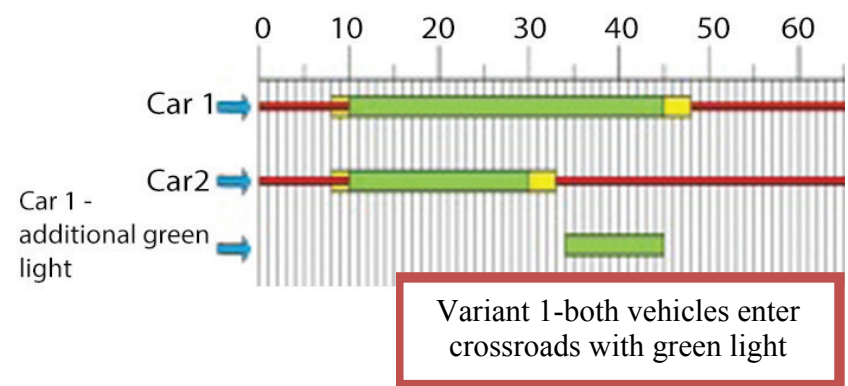

Figure 9.

Both vehicles enter the crossroads with green light.

In case the relative traffic accident occurred in the way described above, the question is why the driver of the vehicle $B$ started intensive braking at the moment while the vehicle $A$ had not even reached the pedestrian crossing on the opposite side of the crossroads, and was in no way threatening the trajectory of vehicle B's movement, so that the vehicle B's driver did not have any reason to react by braking (Baker et al., 1990; Zovak, 2007).

\subsection{Vehicle A Passes with Additional Green Light}

If the exchange of light signalling at the relative crossroads is taken into consideration, it is visible that there is a possibility that the vehicle $A$ entered the crossroads at the moment when for the movement in its direction there was an additional green arrow lit on the traffic lights, which means that at the same time for the direction of the vehicle B's movement there was the red light lit on the traffic lights.

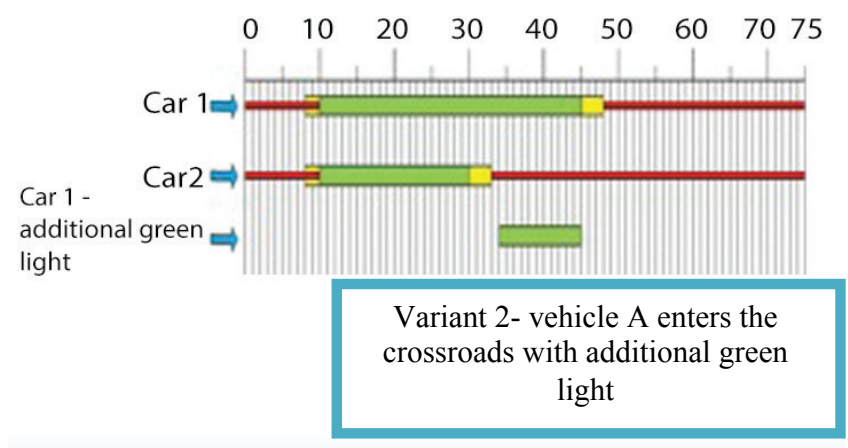

Figure 10.

Vehicle A enters the crossroads with lit additional green arrow. 
In case the relative traffic accident occurred in this way, it is clear that the vehicle B's driver did not undertake the reaction of intensive braking due to the occurrence of vehicle $A$ since he had no reason to do so, since the vehicle $A$ was at that moment entirely located in its traffic lane and had not entered the crossroads (see Fig. 7). Therefore, the only remaining possibility is that the vehicle B's driver, on reaching the point immediately before the crossroads, sighted the yellow light on the traffic lights, and after he had noticed the occurrence of red light on the traffic lights for the movement in its direction, he undertook intensive braking in order to stop the vehicle before the crossroads, which he did not manage to do.

\section{POSSIBILITIES OF CRASH AVOIDANCE}

The vehicle B's driver had the possibility of avoiding the relative traffic accident in the way that at the moment he undertook intensive braking he was moving at the speed of approximately:

$$
\begin{aligned}
V & =3.6 \cdot \sqrt{\left(a_{\max } \cdot t_{s}\right)^{2}+2 \cdot a_{\max } \cdot s}-3.6 \cdot a_{\max } \cdot t_{s}= \\
& =62.16 \mathrm{~km} / \mathrm{h} \approx 17.27 \mathrm{~m} / \mathrm{s}
\end{aligned}
$$

The vehicle A's driver did not have the possibility of avoiding the relative traffic accident since at the moment of his entering the crossroads the additional green arrow was lit for the movement in his direction.

\section{CONCLUSIONS}

All the parameters of the traffic accident have been established through the dynamic analysis of the accident and the given results offered clear guidelines in how to avoid traffic accidents in the future. This particular case deals with the way both drivers reacted on the alteration of the traffic lights at the intersection.

The relative traffic accident occurred at the right angle crossroads of the three streets called: $X, Y$ i Z, in which the traffic was controlled with the use of traffic lights.

The accident occurred in the way that the vehicle B on entering the crossroads in the phase of intensive braking ran with its forward, mainly right hand side into the right hand side of the vehicle $A$, which at that moment was turning left and obstructed the vehicle B's path.

The crash of the vehicles is determined as angular in which the longitudinal axes at the moment of crash were closing the angle of approximately $135^{\circ}$.
The exact place of the crash was in the crossroads, in the extension of the western roadway and western traffic lane of the street $Y$, at the distance of $49.00 \mathrm{~m}$ from PTM southwards and 7.0 $\mathrm{m}$ from the edge of the central island dividing the two roadway lanes of the street $Y$ southwards.

The place of the crash is determined by ending of braking traces of vehicle B's front wheels, traces of roadway imprint as well as the vehicle B's stopped position.

The vehicle $B$ was moving along the western roadway and the western traffic lane of the street $Z$ from the northern direction southwards at the speed of approximately $19.48 \mathrm{~m} / \mathrm{s} \approx 70.11 \mathrm{~km}$ $/ h$.

The vehicle A was moving along the western traffic lane of the eastern roadway of the street $Z$ from the southern direction northwards at the speed of approximately $13.62 \mathrm{~m} / \mathrm{s} \approx 49.03 \mathrm{~km}$ $/ \mathrm{h}$ and on reaching the crossroads was performing a turn to left onto the roadway of the street $Y$.

The vehicle $B$ about 2.31 seconds before the crash was distant from the place of crash approximately $38.91 \mathrm{~m}$ northwards and entirely located on the western traffic lane of the western roadway of the street $Z$.

At the same time interval the vehicle $A$, was distant from the place of accident approximately $31.46 \mathrm{~m}$ southwards, entirely located on the western traffic lane of the eastern roadway of the street Z

The drivers of the vehicles $A$ and $B$ had the possibility of mutual sighting at the distance of at least 100 meters before the place of crash having in mind the directions of both vehicles' movements.

The analysis of the two possible modes of the occurrence of the relative traffic accident: case 1 - when both vehicles pass with the green light and case 2 - when the vehicle A passes with the additional green light, excluding case 1 . Namely, in case 1 the vehicle $B$ 's driver did not have a reason to react on the brake since at the moment of the vehicle $B$ driver's reaction on the brake in the crossroads the vehicle $A$ was entirely located in its own traffic lane.

If the exchange of the light signalling at the relative crossroads is taken into consideration, it is visible that there is the possibility of the occurrence of case 2 , i.e. that the vehicle $A$ entered the crossroads at the moment when for its directional movement the additional green arrow was lit on the traffic lights, which means that at the moment for the directional movement of the vehicle $B$ the red light was lit on the traffic lights.

In case the relative traffic accident occurred in this way, then it is clear that the vehicle B's driver did not undertake the intensive braking due to the occurrence of the vehicle $A$, but due to the attempt to catch the yellow light on reaching the crossroads, and after having noticed that for his directional movement the red light was lit, her undertook intensive braking to stop before the crossroads, which he did not manage to do. 
The vehicle B's driver had the possibility of avoiding the relative traffic accident in the way that at the moment of undertaking intensive braking he was moving at the speed of approximately $62.16 \mathrm{~m} / \mathrm{s} \approx 17.27 \mathrm{~km} / \mathrm{h}$ or any other lower speed, from which a conclusion can be reached that is he had been moving at the speed of $50 \mathrm{~km} / \mathrm{h}$ as permitted on the relative section, he would have stopped much before the place of the crash.

Vehicle A's driver did not have a possibility of avoiding the relative traffic accident since at the moment of his entering the crossroads for his direction the additional green arrow was lit.

This paper emphasises the need of introducing cameras to the intersections equipped with traffic lights, so as to completely eliminate the dilemma which one of the traffic accident participants entered the intersection while the red light or the green light was on.

\section{REFERENCES}

Baker J. S., Aycock T. L., and Lindquist T., (1990), Lamp Examination for On or Off in Traffic Accidents, vol. 1, Illinois, USA: Northwestern University Traffic Institute.

Coyle, F., (2008), Digital Close-Range Photogrammetry in Motor Vehicle Accident Reconstruction, PhD Thesis, Dublin: Dublin Institute of Technology.
Čović, M. and Zečević, D., (eds.), (1987), Vještačenja u cestovnom prometu, Zagreb: Informator.

Datentechnik, S., (2010), Operating Manual Version 9.0, Linz, Austria, available at: http://www.pccrash.co.kr/New\%20folder/PC-Crash\%209.0\%20User\%20manual. pdf, [accessed 11 January 2016.].

Kramer, F., (2006), Passive Sicherheit von Kraftfahrzeugen, ATZ - MTZ Fachbuch, Vieweg+Teubner Verlag.,

http://dx.doi.org/10.1007/978-3-8348-9042-9

Rotim, F., (1989), Elementi sigurnosti cestovnog prometa I, Ekspertize prometnih nezgoda, Svezak 1, Zagreb: Znanstveni savjet za promet HAZU.

Rotim, F., (1992), Elementi sigurnosti cestovnog prometa, Sudari vozila, Svezak 3, Zagreb: Znanstveni savjet za promet HAZU.

Stanivuk, T., Kralj, N. and Šarac, M., (2014), A Case Study of the Court Expert's Investigation Into the Causes of a Road Traffic Accident, Zbornik radova - V. međunarodno savjetovanje "Savremeni trendovi u saobraćaju, logistici i ekologiji održivog razvoja", Travnik, B\&H, May 23 - 24 , pp. 408-416.

Zovak, G., (2007), Rekonstrukcija cestovnih prometnih nezgoda programskim alatima, PhD thesis, Zagreb: University of Zagreb, Faculty of Transport and Traffic Sciences. 